Project Report

\title{
Overseas Support in the Field of Vascular Access
}

\author{
Toshihide Naganuma ${ }^{1,2, *}$, Toru Hyodo ${ }^{2,3}$, Ako Hanaoka ${ }^{2,4}$, Yoshiaki Takemoto ${ }^{1,2}$ and Junji Uchida ${ }^{1,2}$ \\ 1 Department of Urology, Osaka City University, Osaka 545-8586, Japan; \\ ytakemoto@msic.med.osaka-cu.ac.jp (Y.T.); m9492120@msic.med.osaka-cu.ac.jp (J.U.) \\ 2 NGO Ubiquitous Blood Purification International, Yokohama 231-0032, Japan; thyodomd@gmail.com (T.H.); \\ a-masuda@med.osaka-cu.ac.jp (A.H.) \\ 3 Department of Urology, Fureai Clinic Izumi, Yokohama 245-0014, Japan \\ 4 Department of Medical Devices, Osaka City University Hospital, Osaka 545-8586, Japan \\ * Correspondence: m9643361@msic.med.osaka-cu.ac.jp; Tel.: +81-6-6645-3857
}

Citation: Naganuma, T.; Hyodo, T.;

Hanaoka, A.; Takemoto, Y.; Uchida, J. Overseas Support in the Field of Vascular Access. Kidney Dial. 2021, 1, 53-60. https://doi.org/10.3390/ kidneydial1010009

Academic Editor: Giorgina Barbara Piccoli

Received: 18 May 2021

Accepted: 5 August 2021

Published: 10 August 2021

Publisher's Note: MDPI stays neutral with regard to jurisdictional claims in published maps and institutional affiliations.

Copyright: (c) 2021 by the authors. Licensee MDPI, Basel, Switzerland. This article is an open access article distributed under the terms and conditions of the Creative Commons Attribution (CC BY) license (https:// creativecommons.org/licenses/by/ $4.0 /)$.

\begin{abstract}
Since joining the Non-Governmental Organization Ubiquitous Blood Purification International in 2014, professionals who are mainly members of the Japanese Society for Dialysis Therapy (JSDT) have worked toward promoting dialysis therapy in several countries through help with organization of local nephrology societies and conducting educational activities. Since 2016, training at our hospital has been provided for doctors and dialysis staff from these countries as part of the activities of the JSDT. These activities also involve technical training for vascular access (VA) surgery and management. To date, lectures and practical teaching on VA procedures have been given in Cambodia and Vietnam, and a hands-on seminar on echo-guided puncture and VA management was held in Mongolia. In Mongolia and Myanmar, a plan to provide systemic VA surgery education has been developed, at the request of local nephrology societies. Doctors and medical staff from Vietnam, Laos, Cambodia, Nepal and Indonesia have visited our hospital and have observed operations as part of their training. To achieve sustainable medical support and academic activities, we have found it to be important to have a counterpart society in each country, and guidance has been provided when required on organization of a national nephrology society.
\end{abstract}

Keywords: dialysis; overseas support; vascular access

\section{Background}

The motto of the Non-Governmental Organization (NGO) Ubiquitous Blood Purification International (UBPI) is "participate in overseas support activities; do whatever you can, whenever you can; but without pay." Professionals who are mainly members of the Japanese Society for Dialysis Therapy (JSDT) have participated in the activities of the UBPI since 2014 (Figure 1). These participants include urologists, nephrologists, surgeons, clinical engineers, nurses and nutritionists, all of whom have been working toward promoting dialysis therapy in developing countries through assistance with organizing local nephrology societies and performance of educational activities. Since 2016, training for doctors and dialysis staff from several countries has also been provided at Osaka City University Hospital, as part of the activities of the Subcommittee on the Training Program for Dialysis Staff from Developing Countries, which is part of the General Affairs Committee of the JSDT. In this paper, we provide a brief overview of our activities in Japan and overseas, and we discuss the present conditions and difficulties of providing overseas medical support. 


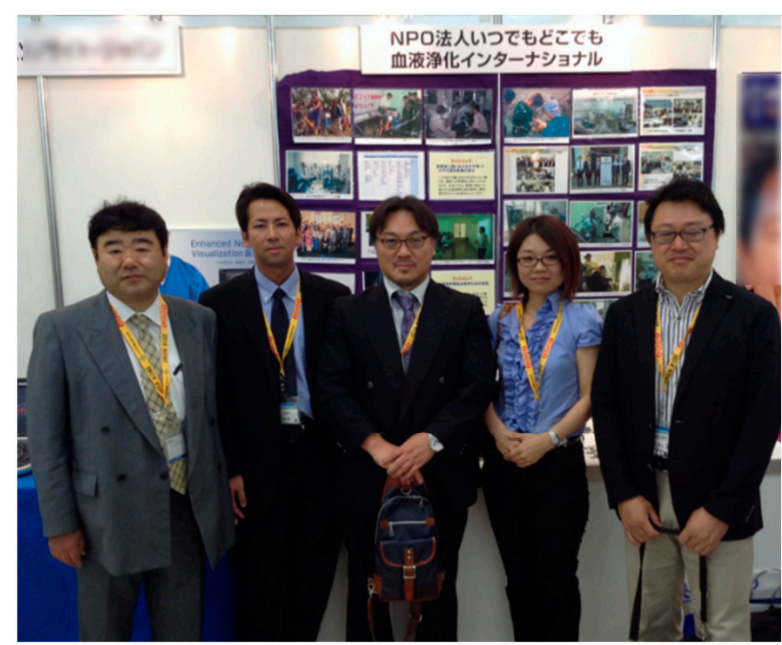

Figure 1. The NGO Ubiquitous Blood Purification International at JSDT 2014 in Kobe.

\section{Activities}

Our NGO-UBPI activities are shown in chronological order in Tables 1 and 2. Visits have been made to five countries (Cambodia, Laos, Mongolia, Myanmar and Vietnam) since 2014 to present lectures and provide medical assistance. A summary of the status of dialysis in each country (original investigation by NGO-UBPI) is shown in Table 3. We have trained physicians from Vietnam, Laos, Cambodia, Indonesia and Nepal as part of our NGO-UBPI activities since 2016. Based on these experiences, the current status and issues with regard to overseas support are reviewed.

Table 1. Timeline of overseas support activities.

(1) 13-15 June 2014 at JSDT 2014 in Kobe: Joined the NGO Ubiquitous Blood Purification International

(2) 28-30 March 2015 in Cambodia: JAC-DSC 2015

(3) 20-23 September 2015 in Cambodia: The Cambodian and International Seminar for Nephrology and Dialysis: First Meeting of the Cambodian Association of Nephrology

(4) 9-10 January 2016 in Cambodia: Received a request for surgery assistance

(5) 8-11 March 2017 in Cambodia: World Kidney Day

(6) 20-24 July 2017 in Cambodia: JAC-DSC 2017

(7) 10-13 August 2017 in Laos: Technical support activities of the Japanese Society for Technology

of Blood Purification (JSTB) Committee on International Affairs

(8) 17-20 November 2017 in Cambodia: Second Meeting of the Cambodian Association of Nephrology

(9) 1-5 August 2018 in Mongolia: Second Mongolia-Japan Joint Seminar on Hemodialysis Technology and Treatment Advances

(10) 6-7 August 2018 in Myanmar: JICA Medical Engineer Training System Reinforcement Program

(11) 23-27 August 2018 in Cambodia: JAC-DSC 2018

(12) 15-18 October 2018 in Vietnam: Vascular Access Meeting

(13) 5-6 August 2019 in Myanmar: JICA Medical Engineer Training System Reinforcement Program

(14) 22-23 August 2019 in Cambodia: JAC-DSC 2019

(15) 28-31 August 2019 in Mongolia: Third Mongolia-Japan Joint Seminar on Hemodialysis Technology and Treatment Advances

Table 2. Timeline of visits of trainees.

(1) 13-20 March 2016: Three doctors from Hanoi, Vietnam

(2) 19-26 February 2017: Two doctors from Ho Chi Minh City, Vietnam

(3) 18-25 February 2018: Two doctors from Laos and two doctors from Cambodia

(4) 17-25 February 2019: Two doctors from Indonesia and one doctor from Nepal 
Table 3. Summary of dialysis in Cambodia, Laos, Mongolia, Myanmar and Vietnam (original investigation by UBPI).

\begin{tabular}{|c|c|c|c|c|c|}
\hline Item & Cambodia & Laos & Mongolia & Myanmar & Vietnam \\
\hline Population & 16.5 million (2019) & 6.9 million (2015) & 3.2 million (2018) & 54 million (2019) & 96.2 million (2019) \\
\hline Health insurance coverage & $\begin{array}{l}\text { Maintenance HD is } 100 \% \text { out } \\
\text { of pocket. }\end{array}$ & $\begin{array}{c}\text { Up to } 6 \text { HD sessions are covered } \\
\text { by the government, but } 100 \% \text { out } \\
\text { of pocket thereafter. }\end{array}$ & $\begin{array}{l}\text { HD is covered } 100 \% \text { by the } \\
\text { government. }\end{array}$ & $\begin{array}{l}\text { At public hospitals, } 1 \mathrm{HD} \text { session is } \\
\text { free of charge. At private hospitals, } \\
10 \text { USD is covered by the government } \\
\text { and } 35 \text { USD is out of pocket. }\end{array}$ & $\begin{array}{l}80 \% \text { of medical expenses are } \\
\text { covered by the government. }\end{array}$ \\
\hline Cost of 1 HD session & 45-60 USD & 50-70 USD & 50 USD & 45 USD & 25 USD (5 USD out of pocket) \\
\hline Dialyzer reuse frequency & 6 times & 10-12 times & Single use & Up to 8 times & 6 times \\
\hline Length of 1 HD session & $4 \mathrm{~h}$ & $4 \mathrm{~h}$ & $4 \mathrm{~h}$ & $4 \mathrm{~h}$ & $3.5-4 \mathrm{~h}$ \\
\hline Frequency per week & $\begin{array}{l}\text { 1-3 times (according to the } \\
\text { patient's financial status) }\end{array}$ & $\begin{array}{l}\text { 1-3 times (according to the } \\
\text { patient's financial status) }\end{array}$ & 3 times & $\begin{array}{l}\text { 1-3 times (according to the patient's } \\
\text { financial status) }\end{array}$ & 3 times \\
\hline Number of HD patients & $500-600(2018)$ & Unknown (2016) & $753(2019)$ & $4000(2019)$ & $22,000(2019)$ \\
\hline Number of PD patients & $0(2019)$ & $3(2018)$ & 66 (2019) & 66 (2019) & $2000(2019)$ \\
\hline
\end{tabular}




\subsection{Cambodia}

Cambodia (total population: 16.5 million) had 500-600 hemodialysis (HD) patients in 2018, and no peritoneal dialysis (PD) patients. However, we have had considerable success in Cambodia, after initially providing assistance with establishment of the Cambodia Association of Nephrology (CAN), as there was originally no counterpart organization for the support activities. Travel to Cambodia was often facilitated through an education program referred to as JAC-DSC (Japanese Assistance Council for establishing Dialysis Specialists in Cambodia) (Figure 2a), and we also performed vascular access (VA) procedures during these visits (Figure $2 \mathrm{~b}$ ). The first author (TN) has visited Cambodia eight times. Initially, we paid our own travel expenses, but now the university covers this cost. TN performed a percutaneous transluminal angioplasty (PTA) in 2017, which was the first to be performed in Cambodia, and for this reason he appeared on television (Figure 2c). Six doctors from the Japanese Society for Dialysis Access (JSDA) have now visited Cambodia 18 times in total in 6 years and performed VA procedures on 44 patients. Because we currently cannot travel to Cambodia due to the COVID-19 pandemic, we plan to hold lectures and educational activities online, in cooperation with the CAN.

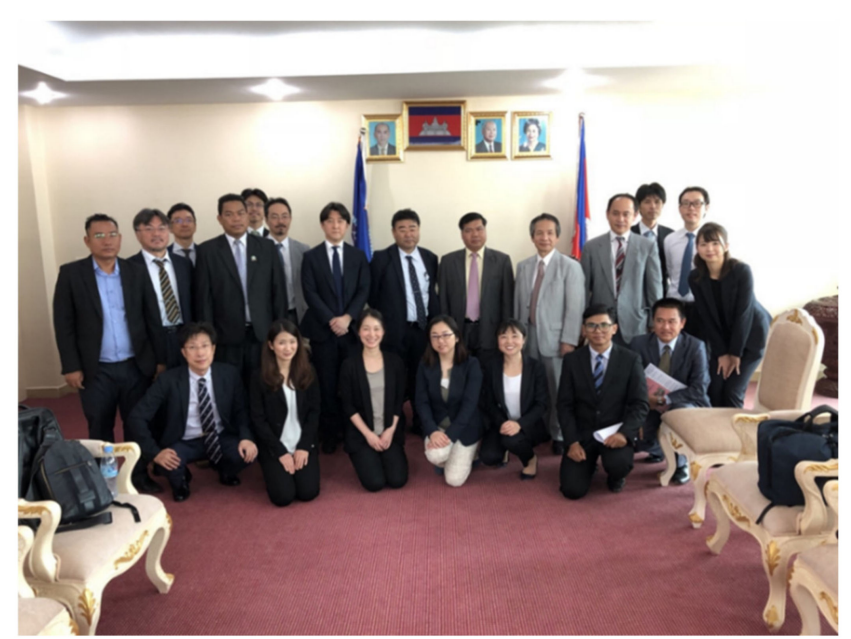

(a)

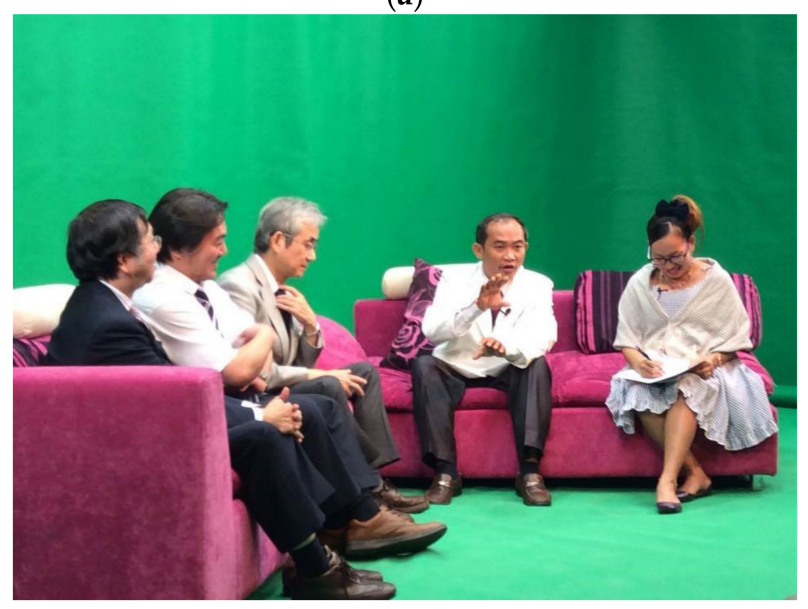

(c)

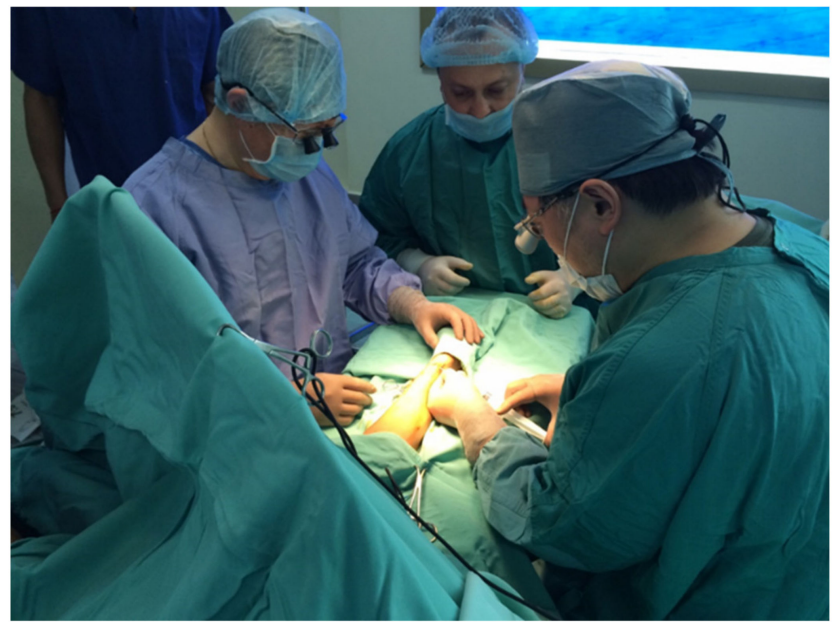

(b)

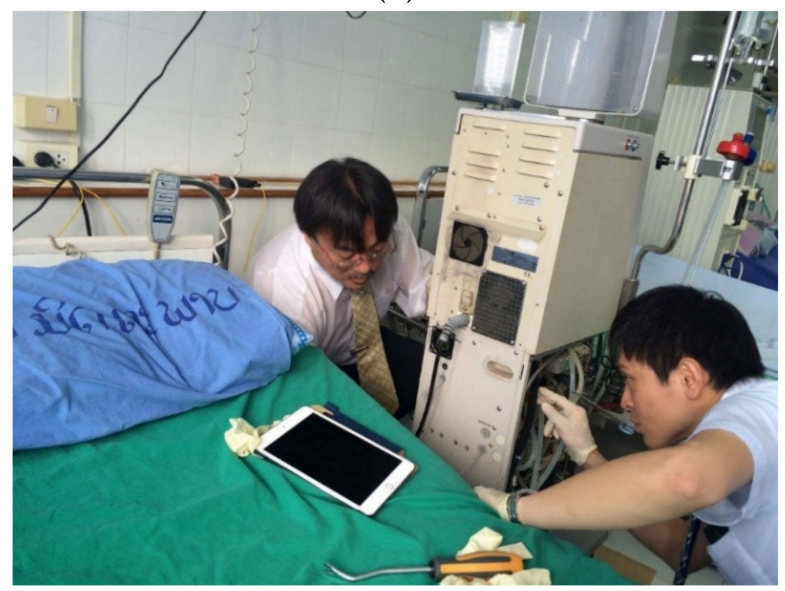

(d)

Figure 2. Cont. 


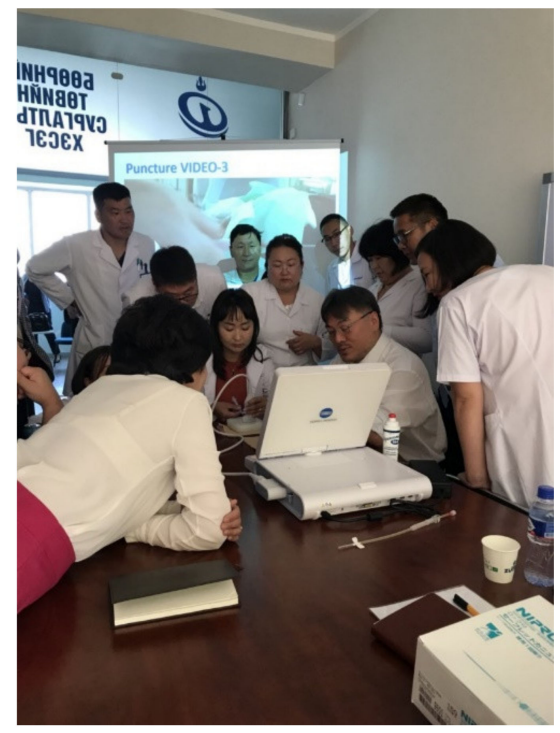

(e)

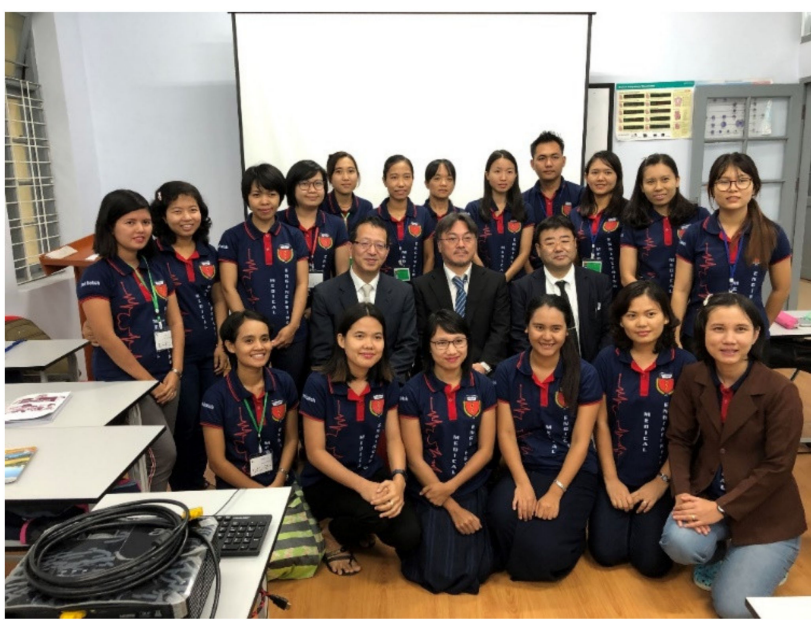

(f)

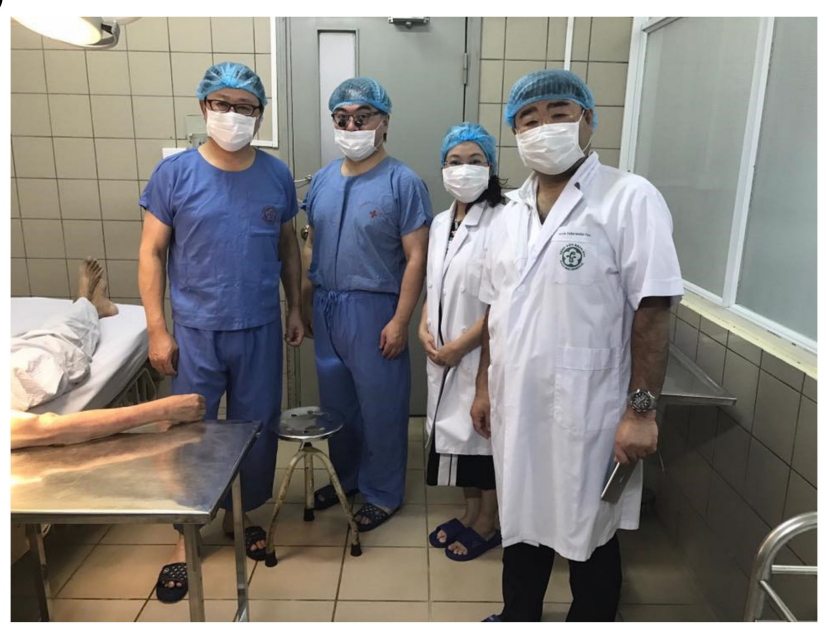

(g)

Figure 2. (a) JAC-DSC 2018 in Cambodia. (b) A request for surgery assistance. (c) Appearance on television in Cambodia. (d) Installation of endotoxin retentive filters in Laos. (e) Hands-on seminar in Mongolia. (f) JICA Medical Engineer Training System Reinforcement Program in Myanmar. (g) Vascular Access Meeting in Vietnam.

\subsection{Laos}

Laos (total population: 6.9 million) had an unknown number of HD patients based on 2016 national data, and the country has limited dialysis therapy compared to other countries. Therefore, we first helped to establish the Laos Society of Nephrology (LSN) as our counterpart (Video S1). The first author (TN) has visited Laos only once, in 2017, when it was decided to establish the LSN. We have volunteered to install endotoxin retentive filters for dialysis fluid purification (Figure 2d), but we have yet to provide training in VA procedures. We planned to visit Laos in spring 2020, but this visit has been postponed due to COVID-19. Due to this restriction, we plan to hold lectures online for the time being.

\subsection{Mongolia}

Mongolia (total population: 3.2 million) had 753 HD patients and 66 PD patients as of 2019, but these numbers have recently increased. The first author (TN) has visited Mongolia twice, and gave a lecture and performed a hands-on echo (Figure 2e) during both of these visits. This year (2020) the Mongolian Society of Nephrology asked us to provide training in VA procedures, but this has been postponed due to COVID-19. We currently plan to conduct educational activities online. 


\subsection{Myanmar}

Myanmar (total population: 54 million) had about 4000 HD patients and 66 PD patients as of 2019. We have participated in Japan International Cooperation Agency (JICA) activities from 2018 (Figure 2f). Prof. Khin Thida Thwin, chairman of the Myanmar Nephro-Urology Society, requested technical training for VA procedures this year (2020), but this has been postponed due to COVID-19 and the military coup. In view of these concerns, we currently are planning to perform educational activities online.

\subsection{Vietnam}

Vietnam (total population: 96.2 million) had recent increases to 22,000 HD patients and 2000 PD patients as of 2019. The first author (TN) attended the First VA for Dialysis Meeting in 2018 and performed a hands-on echo as well as a live arteriovenous fistula and PTA operation (Figure 2g) after the meeting. Currently, there are plans to create a national database, which we intend to support.

\subsection{Acceptance of Trainees}

We have hosted doctors and staff from Vietnam (five doctors), Laos (two doctors), Cambodia (two doctors), Nepal (one doctor) and Indonesia (two doctors) for a total of four times to provide VA training (Figure 3). We hope to restart this program as soon as the pandemic is contained.

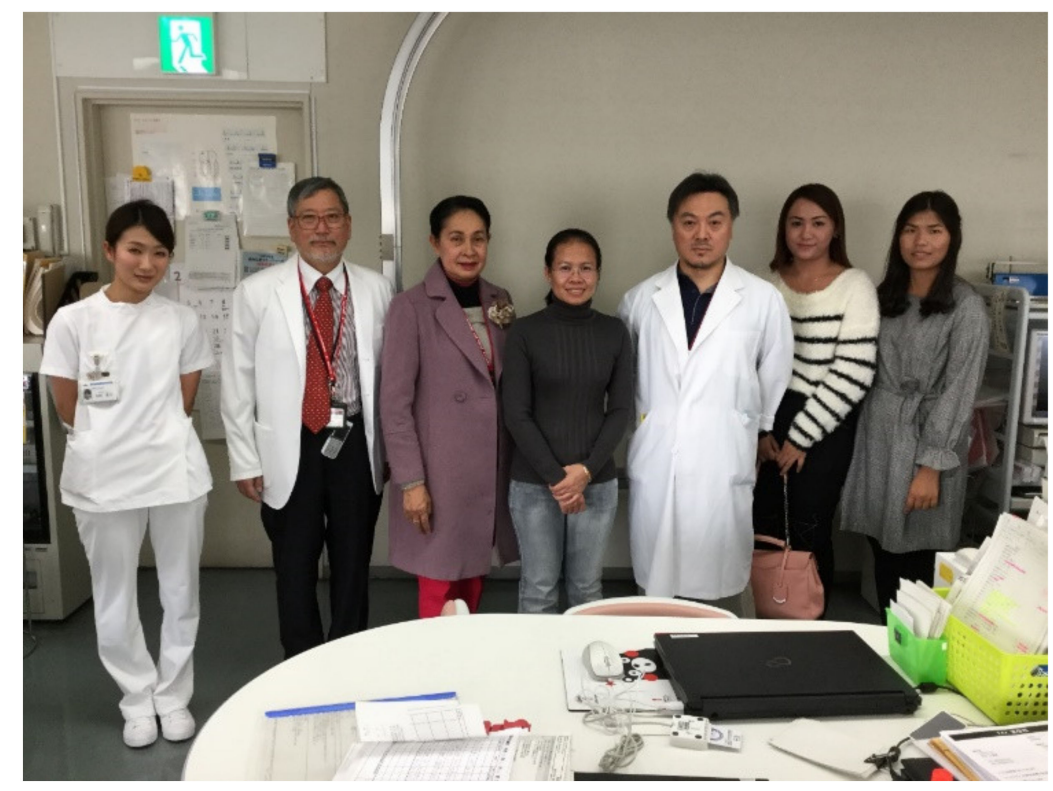

Figure 3. Acceptance of trainees in 2018.

\section{Discussion}

As surgeons involved in overseas medical support activities, we often provide technical training for VA surgery and management, and we have given lectures and taught about VA procedures in Cambodia and Vietnam. In Mongolia, we held a hands-on seminar on echo-guided puncture and VA management. In Mongolia and Myanmar, we have plans to provide systemic VA surgery education at the request of the national nephrology societies. We have also hosted doctors and medical staff from Vietnam, Laos, Cambodia, Nepal and Indonesia, and these doctors have observed operations in our hospital as part of their training. In practice, it is difficult to convey VA procedures in a short time and the trainees have often only been able to observe operations. However, these activities provide medical professionals with an opportunity to acquire new knowledge. Greater efforts to devise systematic training of experts in VA procedures are needed, with consideration on the health care system and the financial conditions in each country. 
In attempting to provide sustainable medical support, we have become particularly aware of the need for a scientific organization to act as a counterpart. Some countries did not have such an organization, and it was important to create a national nephrology society to prevent our support from going to individuals or private organizations. Working through a national society also provides the basis for fair recommendations when selecting trainees to visit Japan. In this regard, the establishment of national societies of nephrology in Cambodia and Laos may be one of the most important outcomes of our work.

Another difficulty in hosting trainees in Japan is the need to have someone in charge of logistics, since we are basically running a hand-made training program. Challenges include meeting and dropping off trainees at the airport, providing transport to and from the hospital, and managing schedules. Improvements in these areas have been made by outsourcing some tasks to travel agencies. It is also difficult to have visiting professionals perform medical procedures in Japan, but it is important to provide an opportunity for visitors to observe and learn, so as to raise their motivation through these experiences.

Financial support is also important in conducting sustainable NGO-UBPI activities. Our work was initially paid for out of pocket, but now our university covers some of the costs, if certain conditions are met and prescribed procedures followed. The university has recognized our activities, and our endeavors in Myanmar [1] and Cambodia [2] are posted on the university website. Recently, we have obtained funding from academic societies such as the Japanese Society for Dialysis Therapy (JSDT), Japanese Society for Technology of Blood Purification (JSTB) and International Society of Nephrology (ISN). We have also been able to conduct activities as part of a Japan International Cooperation Agency (JICA) project. Moreover, the NGO-UBPI is an academic organization, and we have published papers on our outcomes [3,4] and presented papers at dialysis-related meetings (Figure 4). Such academic activities are important, and ours were recently featured in an ISN public affairs publication [5].

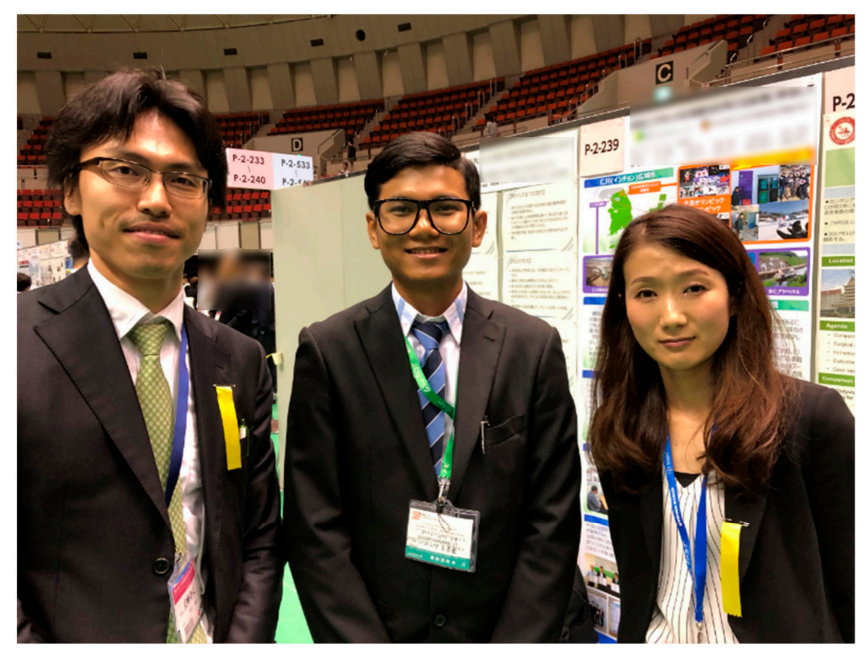

Figure 4. Presentation at JSDT 2018.

\section{Conclusions}

To achieve sustainable medical support and academic activities, we have found it to be important to have a counterpart society in each country, and guidance has been provided when required on organization of a national nephrology society. For us, it is difficult to participate in overseas support activities while holding a regular job, but it is very rewarding work. We hope to continue to offer medical support where our skills can be put to use, and we encourage others to take part in these activities.

Supplementary Materials: The following are available online at https://www.mdpi.com/article/10 .3390/kidneydial1010009/s1, Video S1: Negotiations to establish the Laos Society of Nephrology. 
Author Contributions: T.N. and T.H. contributed to the concept, design, data acquisition, interpretation, and writing. A.H., Y.T. and J.U. reviewed and revised the manuscript. All authors have read and agreed to the published version of the manuscript.

Funding: This research received no external funding.

Institutional Review Board Statement: Not applicable.

Informed Consent Statement: Not applicable.

Data Availability Statement: Not applicable.

Acknowledgments: We thank the participants for providing their clinical information.

Conflicts of Interest: The authors declare that they have no competing interests.

\section{References}

1. Active Exchanges with Myanmar, a Country Drawing Attractive Attention. Available online: https://www.osaka-cu.ac.jp/ja/ news/2019/copy_of_190830 (accessed on 8 May 2021).

2. Medical Staff also Play Active Roles! Medical Support for Kidney Failure in Cambodia. Available online: https://www.osaka-cu. ac.jp/ja/international/news/2019/i3lae9 (accessed on 8 May 2021).

3. Kokubo, K.; Kobayashi, K.; Urabe, S.; Matsubara, H.; Naramura, T.; Wakai, H.; Naganuma, T.; Nakajima, F.; Shibahara, N.; Hyodo, T.; et al. Support for Dialysis Therapy in Vietnam, Cambodia, and Myanmar by Japanese Societies in the Field of Blood Purification. Blood Purif. 2017, 44, 55-61. [CrossRef] [PubMed]

4. Naganuma, T.; Takemoto, Y. Prospects for Vascular Access Education in Developing Countries: Current Situation in Cambodia. Contrib. Nephrol. 2017, 189, 110-113. [PubMed]

5. Ethier, I.; Johnson, D.W.; Bello, A.K.; Ye, F.; Osman, M.A.; Levin, A.; Harris, D.C.; Kerr, P.; Liew, A.; Wong, M.G.; et al. International Society of Nephrology Global Kidney Health Atlas: Structures, organization, and services for the management of kidney failure in Oceania and South East Asia. Kidney Int. Suppl. 2021, 11, e86-e96. [CrossRef] [PubMed] 